\title{
Michael Hillgruber
}

Die pseudoplutarchische Schrift

De Homero

Teil 1 


\title{
Beiträge zur Altertumskunde
}

\author{
Herausgegeben von \\ Ernst Heitsch, Ludwig Koenen, \\ Reinhold Merkelbach, Clemens Zintzen
}

Band 57

\section{需}

B. G. Teubner Stuttgart und Leipzig 


\title{
Die pseudoplutarchische Schrift De Homero
}

\author{
Teil 1 \\ Einleitung und Kommentar \\ zu den Kapiteln 1-73 \\ Von \\ Michael Hillgruber
}

\section{奄}

B. G. Teubner Stuttgart und Leipzig 1994 
Die Deutsche Bibliothek - CIP-Einheitsaufnahme

Hillgruber, Michael:

Die pseudoplutarchische Schrift De Homero / von Michael Hillgruber. - Stuttgart; Leipzig: Teubner.

Zugl.: Bern, Univ., Habil.-Schr., 1992/93

Teil 1. Einleitung und Kommentar zu den Kapiteln 1-73. - 1994

(Beiträge zur Altertumskunde; Bd. 57)

ISBN 3-519-07606-3

NE: GT

Das Werk einschließlich aller seiner Teile ist urheberrechtlich geschützt. Jede Verwertung außerhalb der engen Grenzen des Urheberrechtsgesetzes ist ohne Zustimmung des Verlages unzulässig und strafbar.

Das gilt besonders für Vervielfältigungen, Übersetzungen, Mikroverfilmungen und die Einspeicherung und Verarbeitung in elektronischen Systemen.

(C) B. G. Teubner Stuttgart 1994

Printed in Germany

Druck und Bindung: Röck, Weinsberg 


\section{Für Heidrun}

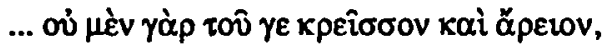

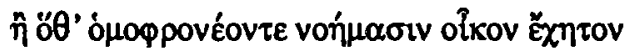

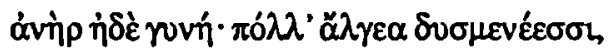

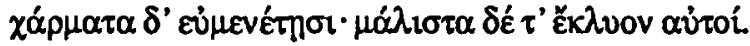

(Od. 6,182-185) 
